\title{
Theoretical Study on Quantitative Characterization of Interlayer Interference in Multi-Layer Commingled Production
}

\author{
Pengfei Mu, Shaopeng Wang, Jie Tan, Hanqing Zhao, Li'an Zhang \\ Bohai Oilfield Research Institute of CNOOC Ltd.-Tianjin Branch, Tianjin, China \\ Email: 4687610@qq.com
}

How to cite this paper: Mu, P.F., Wang, S.P., Tan, J., Zhao, H.Q. and Zhang, L.A. (2021) Theoretical Study on Quantitative Characterization of Interlayer Interference in Multi-Layer Commingled Production. Journal of Power and Energy Engineering, 9, 21-29.

https://doi.org/10.4236/jpee.2021.94002

Received: March 8, 2021

Accepted: April 9, 2021

Published: April 12, 2021

Copyright $\odot 2021$ by author(s) and Scientific Research Publishing Inc. This work is licensed under the Creative Commons Attribution International License (CC BY 4.0).

http://creativecommons.org/licenses/by/4.0/

\begin{abstract}
$\mathrm{X}$ oilfield is a typical layered reservoir with a large vertical span and many oil-bearing formations. There are significant differences in reservoir types and fluid properties among various formations. The interlayer interference is severe in the development process. At present, the interlayer interference research based on dynamic monitoring data cannot meet development adjustment needs. Combined with the field test results, through the indoor physical simulation experiment method, dynamic inversion method, and reservoir engineering method, this paper analyzes the main control factors and interference mechanism of interlayer interference, studies the variation law of interference coefficient, improves and forms the quantitative characteristic Theory of interlayer interference in multi-layer commingled production, and provides theoretical guidance for the total adjustment of the middle strata division in the oilfield.
\end{abstract}

\section{Keywords}

Thin Interbedded Reservoir, Multi-Layer Production, Interbedded Interference, Quantitative Characterization, Theoretical Research

\section{Preface}

$\mathrm{X}$ oilfield is a typical layered reservoir with long vertical oil-bearing intervals and many oil-bearing formations. There are significant differences in reservoir types and fluid properties among various formations. A set of development modes of large well spacing and multi-layer co-production were adopted in the early stage, resulting in serious interlayer interference in the development process. At present, there are many studies on interlayer interference. However, most of the 
conclusions are only applicable to single-phase flow, or only for a particular water cut stage, or qualitatively describe the interference phenomenon of each stage after roughly dividing the production stage according to the field situation [1] [2] [3], which has little guiding significance for actual production [4] [5] [6] [7] [8]. Combined with the field test results, through the indoor physical simulation experiment method, dynamic inversion method, and reservoir engineering method, this paper analyzes the main control factors and interference mechanism of interlayer interference, studies the variation law of interference coefficient, improves and forms the quantitative characteristic theory of interlayer interference in multi-layer commingled production, and provides theoretical guidance for the total adjustment of the middle strata division in the oilfield.

\section{Study on the Mechanism of Interlayer Interference}

\subsection{Study on Oil Displacement Efficiency of Multi-Layer Parallel Connection Based on Physical Model Experiment}

Because of the development problems caused by the thickness, physical properties, fluid and pressure differences of each layer in a thin interbedded reservoir, the visual, physical simulation experiment of multi-layer water flooding is carried out to analyze the displacement efficiency of multi-layer combined production to provide theoretical support for the research of oilfield development plan. The physical models with different physical properties and thicknesses are filled to simulate thinly interbedded reservoirs (or different physical models with different viscosity are used to simulate oil saturation to form the fluid difference between layers). The sand-filled pipe is used to inject water at one end at a constant flow rate through joint injection and anti-nine-point area well pattern development. During the experiment, the change of production speed and injection pressure is recorded to reflect the change of interlayer interference under the condition of combined production (see Figure 1).

Through the multi-layer parallel model experiment, it can be seen that with the increase of permeability level, viscosity level, thickness, and interlayer pressure level, the low permeability layer, high viscosity layer, thin difference layer, and deficit layer is suppressed, and the surface interlayer interference is intensified (see Figure 2).
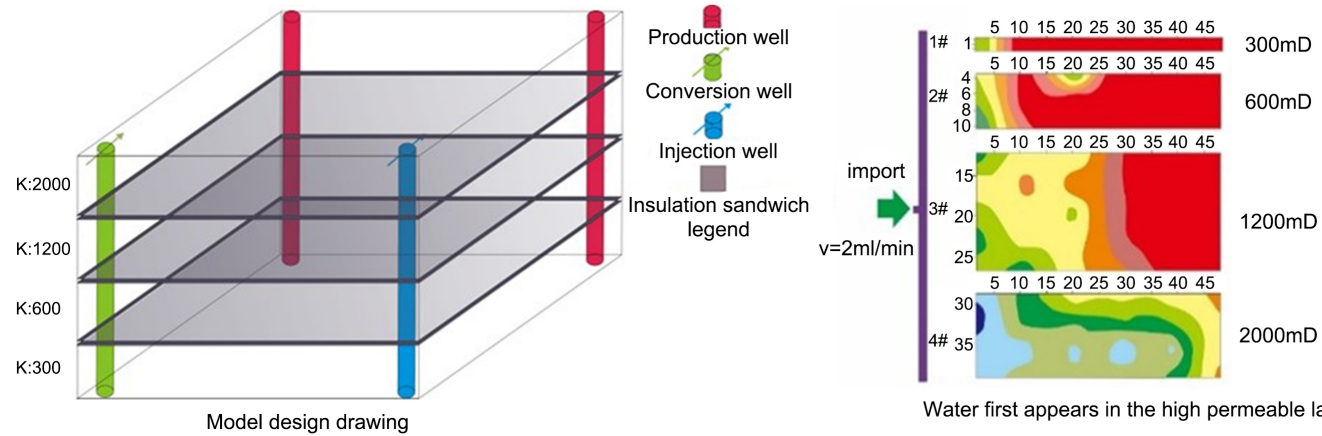

Water first appears in the high permeable layer, then in the low permeable layer

Figure 1. Four-layer parallel displacement experiment diagram. 


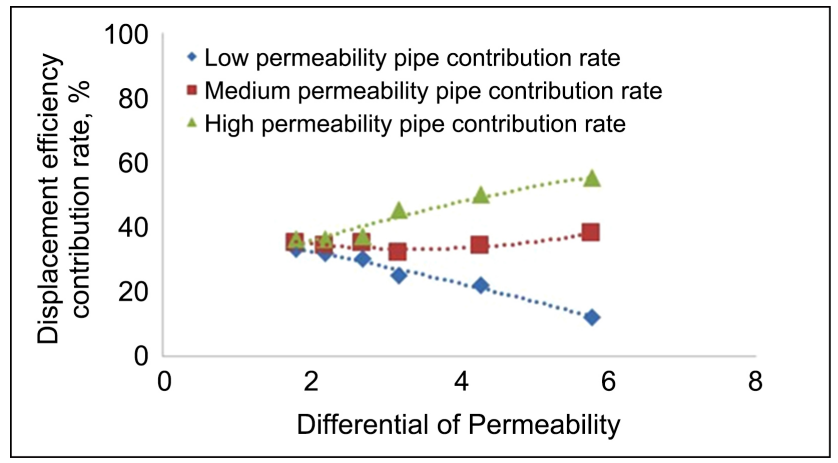

(a)

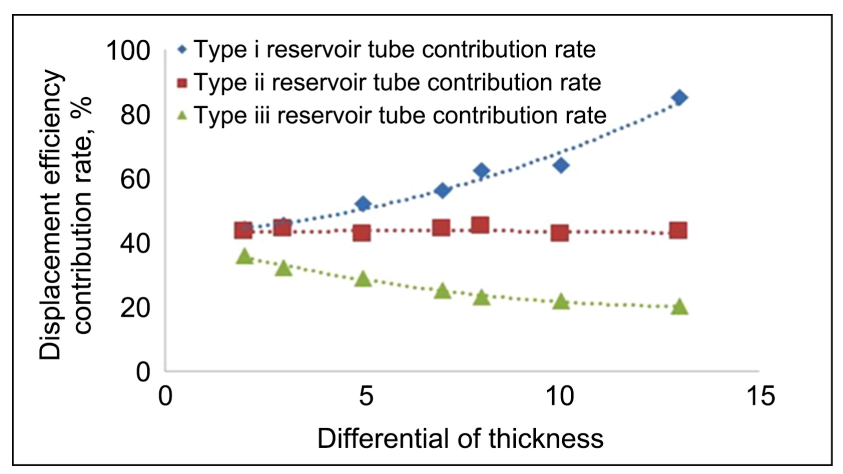

(c)

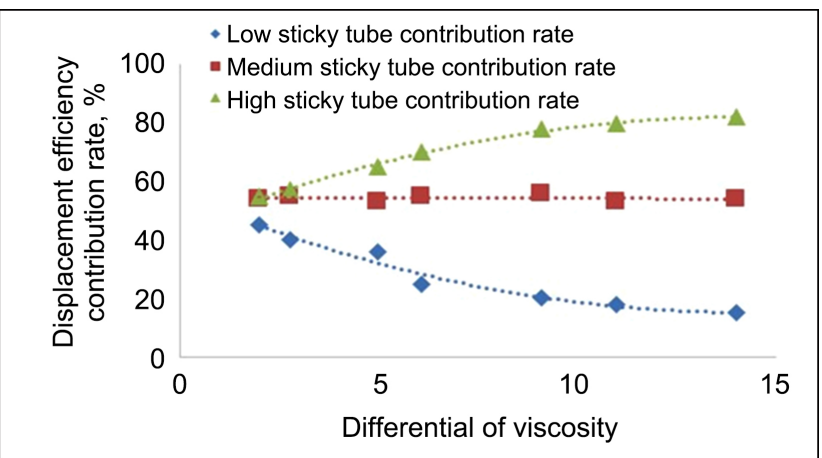

(b)

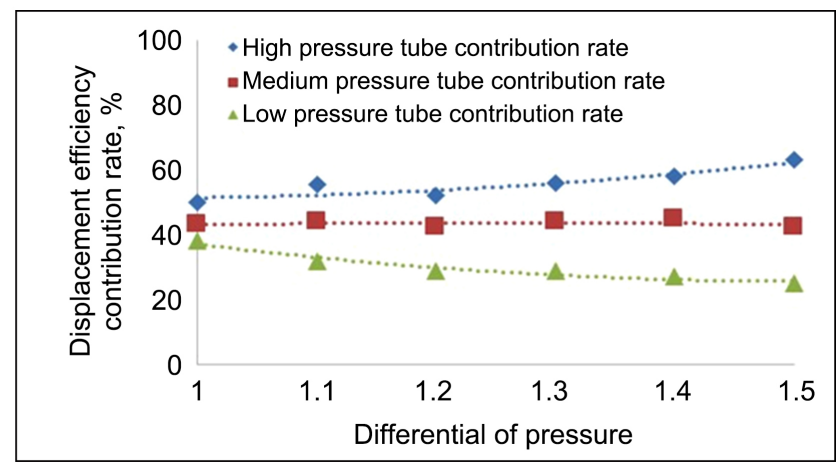

(d)

Figure 2. Comparison diagram of oil displacement efficiency of parallel multi-pipe displacement (different factors). (a) Differential of permeability; (b) Differential of viscosity; (c) Differential of thickness; (d) Differential of pressure.

\subsection{Study on Sweep Efficiency of Multi-Layer Commingled Production Based on Reservoir Engineering Method}

In the development process of Multi-layer Reservoir, due to the difference of physical properties, fluid, reservoir, and pressure between layers, the seepage resistance of different layers is different, the advanced speed of the water drive front is different, and the development effect is different. Based on Buckley Leverett's Theory, a theoretical model of multi-layer waterflood development is established. The Multi-layer Reservoir co-production development effect's influencing factors to provide theoretical guidance for the development adjustment of an oil field in the layered system [1] [9] [10].

Based on oil-water two-phase percolation theory, a water drive oil model of multi-layer reservoir is established to simulate the combined production and separate production of Multi-layer Reservoir under the condition of constant liquid volume and to solve the production liquid (oil) volume, production liquid (oil) index, percolation resistance, the production process of each oil layer in different development stages.

The production of multi-layer oil displacement model is:

$$
Q_{o}=\sum_{i=1}^{M} \frac{2 \pi k_{i} h_{i} \Delta P}{\int_{r_{f i}}^{R_{e v}} \frac{1}{\left(\frac{k_{r o}}{\mu_{o i}}+\frac{k_{r w}}{\mu_{w}}\right) r} d r}+\sum_{i=M+1}^{N} \frac{2 \pi k_{i} h_{i} \Delta P}{\int_{r_{f i}}^{R_{e v}} \frac{1}{\left(\frac{k_{r o}}{\mu_{o i}}+\frac{k_{r w}}{\mu_{w}}\right) r} \mathrm{~d} r+\mu_{o i} \ln \left(\frac{r_{f i}}{r_{w}}\right)}
$$


The vertical sweep coefficient is:

$$
E_{v}=\frac{\sum_{i=1}^{M} \pi R_{e v}^{2} h_{i} \varnothing_{i}+\sum_{i=M+1}^{N} \pi\left(R_{e v}^{2}-r_{f i}^{2}\right) h_{i} \varnothing_{i}}{\sum_{i=1}^{M} \pi R_{e v}^{2} h_{i} \varnothing_{i}}
$$

The recovery degree of the reservoir is:

$$
\eta=\frac{\sum_{i=1}^{M} \pi R_{e v}^{2} h_{i} \varnothing_{i}\left(\overline{S_{w i}}-S_{w c i}\right)+\sum_{i=M+1}^{N} \int_{o}^{t} Q_{i} \mathrm{~d} t}{\sum_{i=1}^{M} \pi R_{e v}^{2} h_{i} \varnothing_{i}\left(1-S_{w c i}\right)}
$$

where, $Q_{o}$ is commingling production, $\mathrm{m}^{3} / \mathrm{d} ; k_{i}$ is layer i permeability, $\mu \mathrm{m}^{2}$; $h_{i}$ is layer i thickness, $\mathrm{m} ; \mu_{o i}$ is the viscosity of layer i crude oil, $\mathrm{mPa} \cdot \mathrm{s} ; \mu_{w}$ is the viscosity of layer i water, $\mathrm{mPa} \cdot \mathrm{s} ; k_{r o}$ is oil relative permeability; $k_{r w}$ is water relative permeability; $E_{v}$ is longitudinal sweep factor; $\Delta P$ is production pressure differential, $\mathrm{MPa} ; \varnothing_{i}$ is layer i porosity; $R_{e v}$ is supply radius, $\mathrm{m} ; r_{w}$ is wellbore radius, $\mathrm{m} ; r_{f i}$ is layer $\mathrm{i}$ oil-water front, $\mathrm{m} ; \eta$ is reservoir recovery; $\overline{S_{w i}}$ is layer i average water saturation; $S_{w c i}$ is water saturation at the exit of layer $\mathrm{i}$.

As shown in Figure 3, when the difference of thin interbeds, permeability, viscosity, and pressure is larger, the sweep coefficient between combined production and separate production is more significant. However, the increased rate of differential coefficient will gradually slow down. According to the oil field characteristics (sweep coefficient difference is less than 10\%), the ratio of the thin layer to thick layer is less than 0.3 , permeability is less than 5 , viscosity is less than 3, and The pressure difference between layers is less than about 1.2.

\subsection{Characterization of Interlayer Interference Coefficient Based on Dynamic Production Inversion}

Given the characteristics of large well spacing and multi-layer production in most oilfields, such as thickness, reservoir physical properties, fluid properties, and interlayer pressure differences, this paper analyzes the influence of interlayer interference on oil well productivity in different water cut stages of multi-layer production, establishes the quantitative characterization theory of interlayer interference in multi-layer production, and provides guidance for the classification and later adjustment of oil fields.

In this paper, the interference coefficient concept is introduced to describe more intuitively the influence of interlayer interference in different water cut stages on the combined mining effect. The change of interference coefficient with water cut reflects the influence of interlayer interference on the oil well's overall oil production capacity well with the change of water cut [2] [3] [11] [12]. Calculation formula of interference coefficient:

$$
\alpha_{0}=\frac{\sum_{i=1}^{n} J_{d i_{o}}-\sum_{i=1}^{n} J_{h i_{o}}}{\sum_{i=1}^{n} J_{d i_{o}}}
$$

where, $\alpha_{0}$ is interference coefficient; $J_{d i_{o}}$ is oil production index at a single recovery time of layer I; $J_{h i_{o}}$ is layer I oil production index at the time of stratification. 


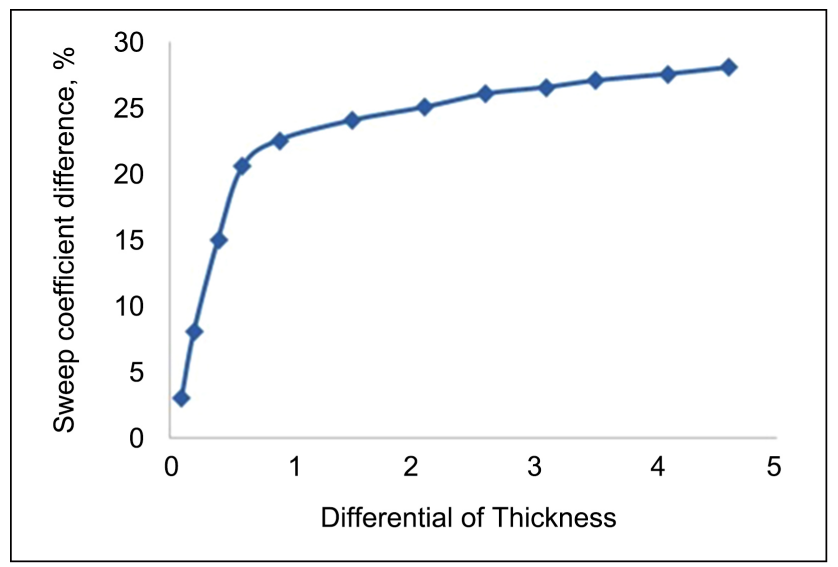

(a)

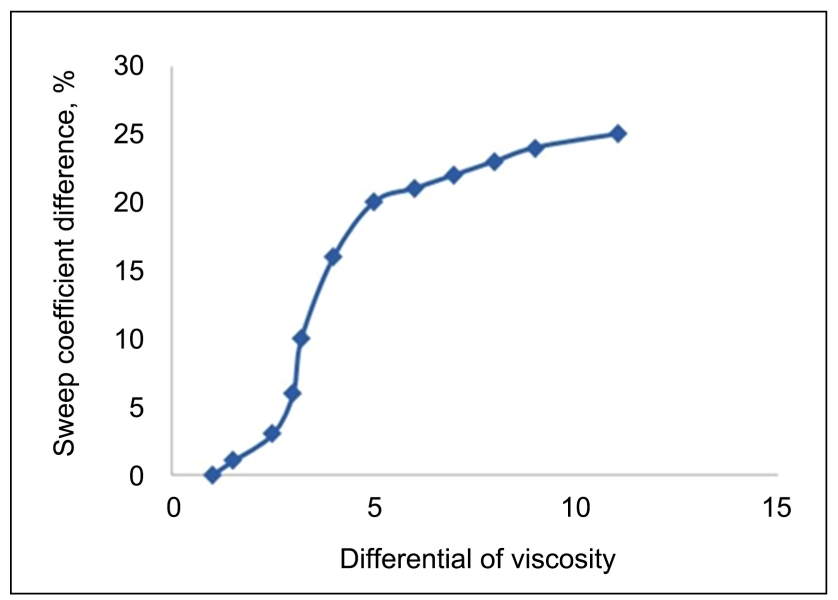

(c)

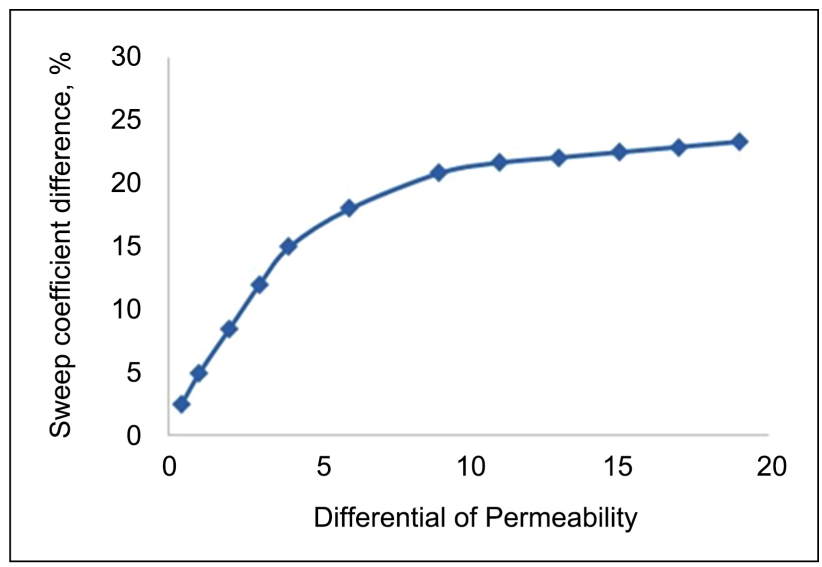

(b)

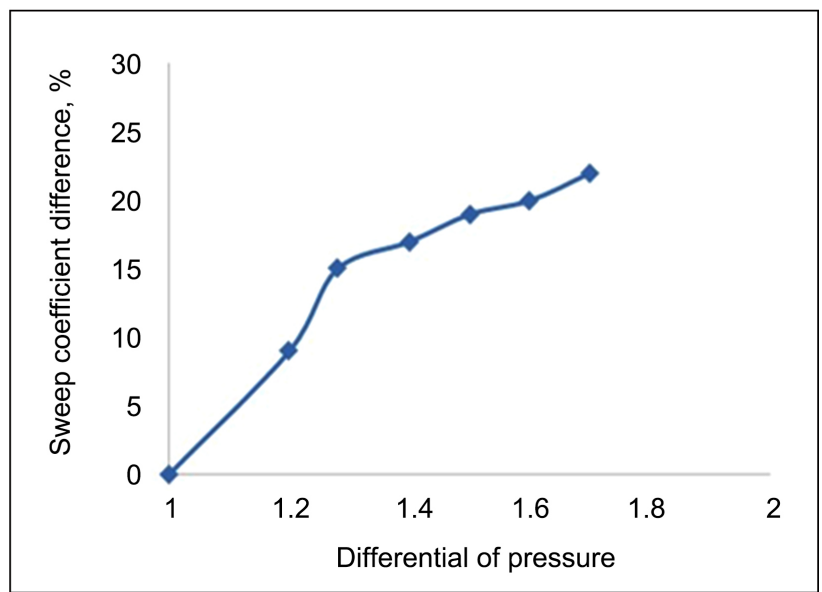

(d)

Figure 3. Comparison of sweep efficiency between combined production and separate production in X oilfield. (a) Ratio of different thin layers; (b) Different permeability levels; (c) Different viscosity levels; (d) Different pressure levels.

By introducing the interference coefficient, the formula of single-layer directional well productivity is modified, and the formula of multi-layer combined production productivity is obtained:

$$
Q_{o}=\frac{542.87\left(1-\alpha_{0}\right) \sum_{i=1}^{n} \frac{K_{i} K_{r o i}\left(P_{e}-P_{w}-G_{i} R_{i e v}\right)}{\mu_{o i} B_{o i}}}{\left(\ln \frac{R_{e v}}{r_{w}}+S\right)}
$$

Formula (5) was further sorted out to obtain the quantitative expression of inter-layer interference coefficient:

$$
\alpha_{0}=1-Q_{o} \frac{\left(\ln \frac{R_{e v}}{r_{w}}+S\right)}{542.87 \sum_{i=1}^{n} \frac{K_{i} K_{r o i}\left(P_{e}-P_{w}-G_{i} R_{i e v}\right)}{\mu_{o i} B_{o i}}}
$$

where, $K_{\text {roi }}$ is oil relative permeability in layer I; $P_{e}$ is supply pressure, MPa; $P_{w}$ is bottom hole flowing pressure, MPa; $R_{\text {iev }}$ is the supply radius at the level 
$\mathrm{I}, \mathrm{m} ; S$ is skin factor; $G_{i}$ is starting pressure gradient, $0.1231 \times\left(\frac{K_{i}}{\mu_{i}}\right)^{-0.6288}$.

The interference between lower layers under different water cut conditions of $\mathrm{X}$ oilfield is analyzed systematically based on the quantitative expression formula of interference coefficient. The interference coefficient evaluation chart of the $\mathrm{X}$ oilfield is formed (see Figure 4). It can be seen that: 1) there is interlayer interference caused by thickness difference, viscosity difference, permeability difference, and interlayer pressure difference in multi-layer production of $\mathrm{X}$ oilfield; 2 ) in the process of multi-layer production The interlayer interference has a noticeable inhibition effect on oil production. With the increase of water content, it is imperative to develop the layered system in the middle and high water cut stage; 3 ) the larger the permeability level difference (viscosity level difference, thickness level difference, pressure level difference), the more pronounced the interlayer interference degree under the same water content. Therefore, to reduce the interference between layers, the layered system is developed for the reservoir with significant permeability difference (viscosity difference, thickness difference, and pressure difference).

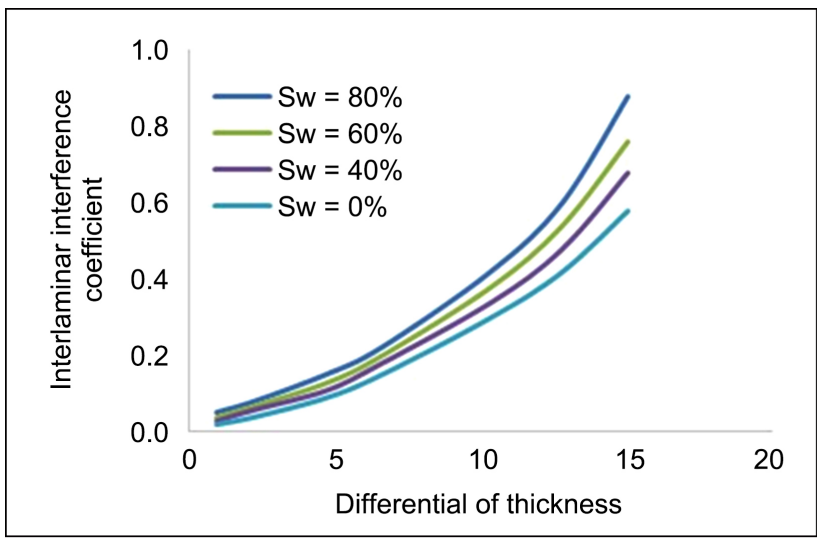

(a)

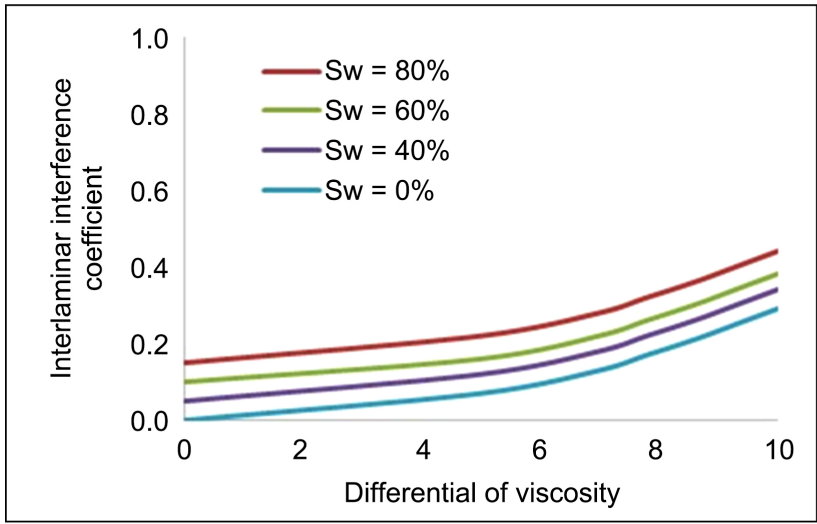

(c)

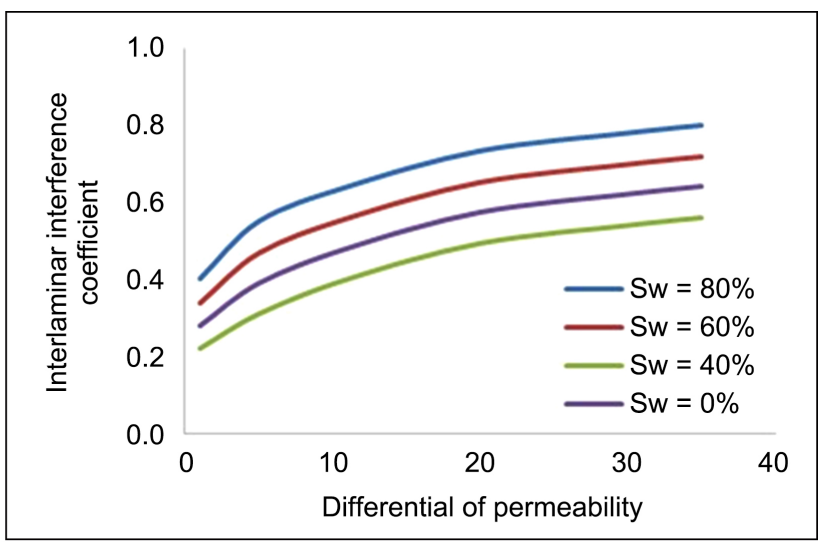

(b)

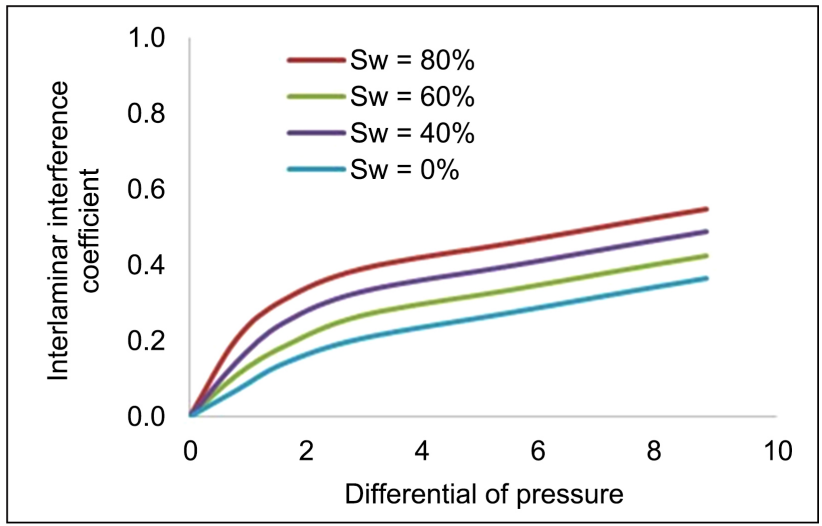

(d)

Figure 4. Evaluation template of interference coefficient between layers with different water cut in X Oilfield. (a) Interference of thickness differential; (b) Interference of permeability differential; (c) Interference of viscosity differential; (d) Interference of pressure differential. 


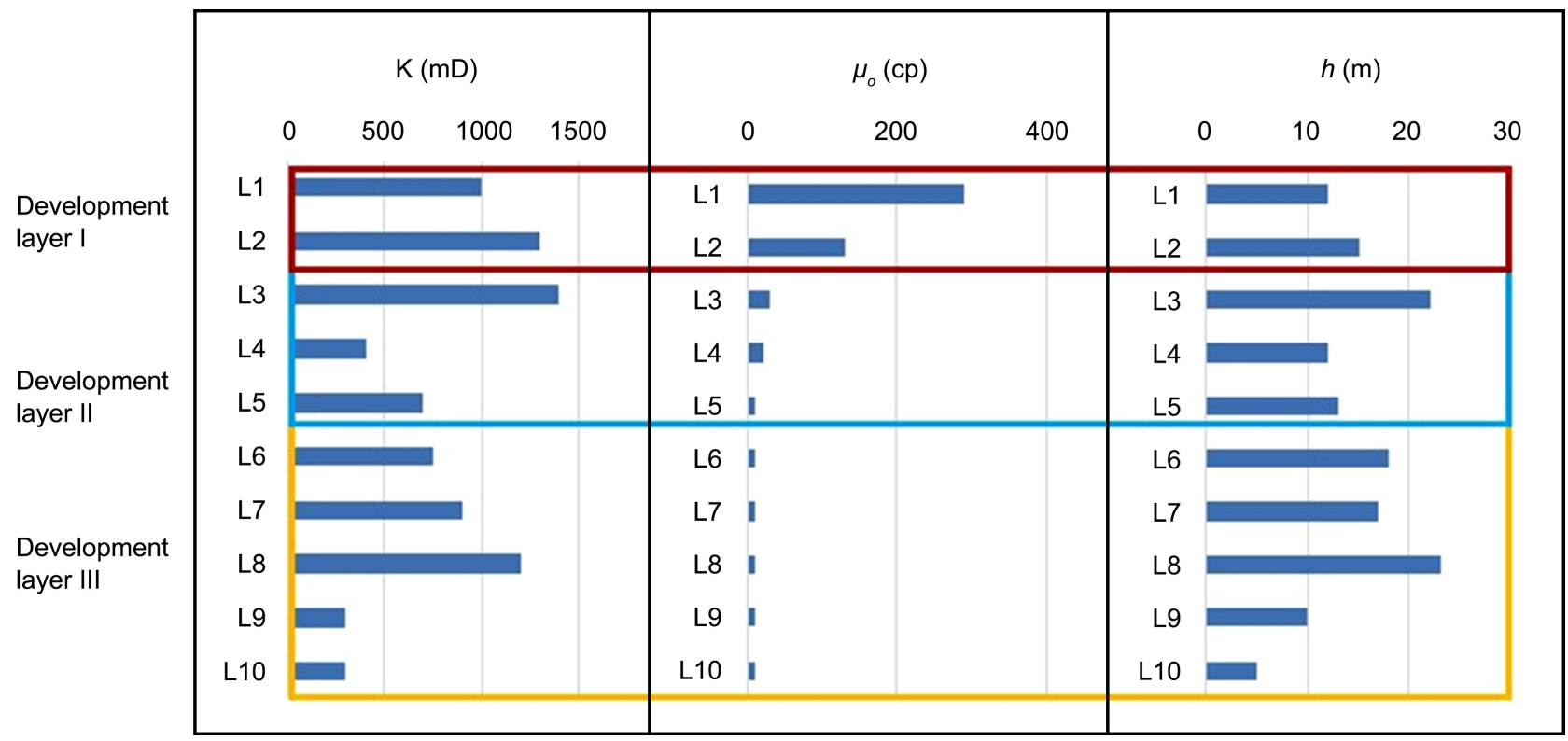

Figure 5. Stratification of X oilfield.

\section{Subdivide the Development Layer Effect}

Thin interbedded sandstone reservoir X oilfield has a long vertical span $(650 \mathrm{~m})$, many oil-bearing series (10 oil formations), and different reservoir types and fluid properties $(10-350 \mathrm{cp}$ ) between each series. In the early stage, to consider both development cost and production effect, the development mode of large well spacing $(350 \mathrm{~m})$, directional well, a set of reservoir series, and combined injection and production was adopted, but due to the substantial heterogeneity of plane and vertical of river facies reservoir The multi-layer mining results in serious interlayer interference. The development strata are divided based on quantitative characterization of oil displacement efficiency, sweep efficiency, and interference coefficient of multi-layer combined production. According to the oilfield's actual situation, the reservoir types, physical properties of the reservoir, fluid properties, and pressure differences of the reservoir are divided into different production layers. The strategy of thoroughly subdividing the development strata by vertical oil and water wells is adopted. The original development strata are adjusted to three development strata, and different reservoir types are adjusted, separate production of soil layers with different fluid properties and different pressure differences (see Figure 5). After the implementation of the plan, the daily oil production will be increased by $2700 \mathrm{~m}^{3} /$ day; the water cut rise rate and natural decline rate will continue to decline for five years, and the water drive recovery rate and reserve production degree will increase year by year. This research result has a specific reference value for similar oil fields.

\section{Conclusions}

In this paper, using a laboratory physical simulation experiment, dynamic inversion method, and reservoir engineering method, the main control factors and 
interference mechanism of interlayer interference are analyzed, and the change rule of interference coefficient is studied. The following conclusions have been reached:

1) According to the multi-layer parallel model experiment, the increase of permeability, viscosity, thickness, interlayer pressure, low permeability layer, high viscosity layer, thin difference layer, and deficit layer is suppressed, and the surface inter-layer interference is intensified.

2) Based on Buckley Leverett's Theory, a theoretical multi-layer water drive development model is established. It is concluded that the larger the differential, permeability differential, viscosity differential, and pressure differential, the more significant the difference of sweep efficiency between $\mathrm{CO}$ production and separate production, but the more significant the difference coefficient, the slower the rate.

3) Because most oilfields adopt the development mode of multi-layer production with large well spacing, the influence of interlayer interference on oil well productivity in different water cut stages of multi-layer production is analyzed; interference chart of interlayer in different water cut stages of multi-layer production is established.

Through this paper's research results, we can provide some theoretical basis and guidance for thin interbed oil fields to divide and adjust the stratigraphic system.

\section{Conflicts of Interest}

The authors declare no conflicts of interest regarding the publication of this paper.

\section{References}

[1] Deng, Y. and Li, X. (2001) Geological Characteristics and Enlightenment of Penglai 19-3 Oilfield. PetroChina Exploration, 6, 68-71.

[2] Su, Y. and Li, T. (2016) Development and Adjustment Practice of Offshore Sandstone Oilfield in High Water Cut Stage. Offshore Oil and Gas, 28, 83-90.

[3] Xu, Z., Shen, C., Chen, Y., et al. (2016) Configuration Characterization of Sandy Braided River Reservoir and Its Control Over Remaining Oil-Taking P Oilfield in Bohai Sea as an Example. Journal of Sedimentation, 34, 375-385.

[4] Deng, Y. (1999) The Difference of Oil and Gas Accumulation between Depression and Uplift in Bohai Bay Basin. Offshore Oil and Gas, China, No. 6, 13-17.

[5] Zhao, W. and Chi, Y. (2000) Regional Distribution and Main Controlling Factors of Petroleum Bearing Strata in Bohai Bay Basin. Journal of Petroleum, 21, 10-15.

[6] Chiyingliu, and Zhao, W. (2000) Cenozoic Strike Slip Structure and Hydrocarbon Accumulation in Bohai Bay Basin. Journal of Petroleum, 21, 14-22.

[7] Xue, Y., Wang, Y. and Zhao, J. (2001) Analysis of Formation Characteristics and Rules of Upper Tertiary Reservoirs in Bohai Sea. Petroleum Exploration and Development, 28, 1-3.

[8] Guo, T., Liu, C., Lv, H., et al. (2001) Geological Characteristics of Penglai 19-3 Oilfield. Petroleum Exploration and Development, 28, 26-28. 
[9] Zhao, X., Wang, Q., Jin, F., et al. (2015) Secondary Exploration Engineering and Its Significance of Oil Rich Depression in Bohai Bay Basin. Petroleum Exploration and Development, 42, 723-733. https://doi.org/10.1016/S1876-3804(15)30075-6

[10] Deng, Y., Xue, Y., Yu, S., et al. (2017) Theory of Shallow Oil and Gas Migration and Accumulation and Discovery of Bohai Oil Field Group. Journal of Petroleum, 38, $1-8$.

[11] Liu, Y., Luo, X., Kang, K., et al. (2016) A New Method for Characterizing Permeability of Sandstone Reservoir Based on Lithofacies Constraints. Petroleum Geology and Recovery, 23, 93-97.

[12] Huang, S., Kang, B., Cheng, L., et al. (2015) Quantitative Characterization of Interlaminar Interference and Productivity Prediction of Directional Wells in Offshore Common Heavy Oil Reservoirs. Petroleum Exploration and Development, 42, 488-495. https://doi.org/10.1016/S1876-3804(15)30046-X 